\section{Algae for Aquaculture and Animal Feeds}

\author{
by Robin J. Shields and Ingrid Lupatsch, \\ Swansea University, UK
}

This article reviews the current state-of-theart for algae use in aquaculture, plus recent developments in algal biomass as a micro- or bulk ingredient in formulated animal feeds (terrestrial livestock and aquaculture species). Microalgae provide an important direct or indirect feed source for early developmental stages of many farmed finfish, shellfish and invertebrate species. Hatcheries typically cultivate microalgae in-house, with commercial concentrates now also being used widely. Different strains of micro- and macroalgae vary in their efficacy within formulated animal feeds, although there is sufficient evidence of good nutritional properties to promote algal biomass as a source of micronutrients or as a bulk feedstuff. High costs of algal biomass compared to commodity feedstuffs currently confine their commercial use to niche animal feed applications; greater availability/lower price, via biofuels and biorefinery would enable more widespread use in future.

\section{Introduction}

Cultivated microalgae have long been integral to the hatchery production of many farmed finfish, shellfish and other commercially important aquaculture species. By contrast, macroalgae are less widely used in aquaculture, although they do provide an important source of nutrition for certain farmed invertebrates, such as sea urchins and abalone.

There is an extensive published literature on the suitability of different algal strains for use in aquaculture hatcheries, their cultivation techniques, methods of delivery and modes of operation (Muller-Feuga et al. 2003a; Muller-Feuga et al. 2003b; Muller-Feuga et al. 2004; Zmora, Richmond 2004; Tredici et al. 2009; Conceição et al. 2010; Guedes, Malcata 2012). Given that detailed reviews already exist, the purpose of the current article is to introduce the biotechnology reader to algae production and use in hatcheries, including recent industry trends and future outlook.

Alongside these well established applications for micro- and macroalgae in aquaculture hatcheries, there is currently a drive to exploit algae in formulated animal feeds, both for aquaculture species and terrestrial livestock. To date, technological developments and commercial applications have mainly focused on algae as a micro-feed ingredient, imparting specific beneficial properties rather than gross nutrients to the recipient animal. However, finite supplies of premium raw materials (particularly fish meal and fish oil) and the promise of much higher available quantities of algal biomass in future (i.e., biofuels agenda) are prompting evaluation of algal biomass as a major ingredient in formulated animal feeds, especially for aquaculture.

Recent scientific findings reviewed herein do indicate good potential for microalgal biomass as a bulk feedstuff for formulated aquaculture feeds, however the future commercial viability of this will depend on available quantity, quality (composition) and cost in relation to currently used commodity materials. There are currently major gaps in supply and price preventing such use of algal biomass and we anticipate these can only be bridged within a major algal biorefineryfor-biofuels framework.

\section{Microalgae Use in Aquaculture Hatcheries}

Aquaculture hatcheries producing juvenile finfish and shellfish for food represent the most numerous microalgal production facilities worldwide. This abundant capacity reflects both the importance of aquaculture for global food production (e.g., accounting for more than $45 \%$ of global food fish production in 2008, Anon. 2010a) and the key role of microalgae as a preferred or obligatory feed source for many aquaculture species, particularly marine finfish and invertebrates (Tredici et al. 2009).

In more traditional, extensive forms of aquaculture, adventitious populations of microalgae are bloomed in ponds or large tanks, which act as mesocosms in which the aquaculture species occupies the highest trophic level. By contrast, intensive aquaculture hatcheries cultivate individ- 
ual strains of microalgae in separate reactors and administer these regularly to the farmed species.

The role of microalgae in aquaculture hatcheries may be summarised as follows:

- All developmental stages of bivalve molluses are directly reliant on microalgae as a feed source. Bivalve hatcheries therefore cultivate a range of microalgal strains for broodstock conditioning, larval rearing and feeding of newly settled spat.

- Farmed gastropod molluscs (e.g., abalone) and sea urchins require a diet of benthic diatoms when they first settle out from the plankton, prior to transferring to their juvenile diet of macroalgae.

- The planktonic larval stages of commercially important crustaceans (e.g., penaeid shrimps) are initially fed on microalgae, followed by zooplanktonic live prey.

- The small larvae of most marine finfish species and some freshwater fish species also initially receive live prey, usually in the presence of a background of microalgae. Depending on whether these microalgae are allowed to bloom within the fish larval rearing tanks, or are added from external cultures, this is referred to as the "green water" or "pseudogreen water" rearing technique.

- The zooplanktonic live prey referred to above are microscopic filter-feeders that are themselves commonly fed on microalgae, although inert formulated feeds have been developed as a more convenient diet form for use by hatcheries.

\subsection{Microalgal Strains Used in Aquaculture Hatcheries}

As referred to in previous reviews, only a small number of microalgal strains are routinely cultured in aquaculture hatcheries, based on practical considerations of strain availability, ease of culture, cell physical characteristics, nutritional

Table 1: Groups, genera and species of major microalgal strains used in aquaculture and their areas of application

\begin{tabular}{|c|c|c|c|}
\hline Group & Genus & Species & Area of application \\
\hline Cyanobacteria & Arthrospira & platensis & FFI \\
\hline \multirow[t]{4}{*}{ Chlorophyta } & Tetraselmis & suecica, chui & $\mathrm{B}, \mathrm{CL}$ \\
\hline & Chlorella & sp., vulgaris, minutissima, virginica, grossii & $\mathrm{R}, \mathrm{FFI}$ \\
\hline & Dunaliella & sp., tertiolecta, salina & FFI \\
\hline & Haematococcus & pluvialis & FFI \\
\hline $\begin{array}{l}\text { Eustigmatophyceae } \\
\text { (Phylum Heterokontophyta) }\end{array}$ & Nannochloropsis & sp., oculata & $\mathrm{R}, \mathrm{GW}$ \\
\hline \multirow[t]{2}{*}{ Labyrinthulea (Phylum Heterokonta) } & Schizochytrium & sp. & RAD \\
\hline & Ulkenia & sp. & RAD \\
\hline \multirow[t]{6}{*}{ Bacillariophyta (diatoms) } & Chaetoceros & calcitrans, gracilis & $\mathrm{B}, \mathrm{CL}$ \\
\hline & Skeletonema & costatum & $\mathrm{B}, \mathrm{CL}$ \\
\hline & Thalassiosira & pseudonana & $\mathrm{B}, \mathrm{CL}$ \\
\hline & Nitzschia & sp. & GU \\
\hline & Navicula & sp. & GU \\
\hline & Amphora & sp. & GU \\
\hline \multirow[t]{2}{*}{ Haptophyta } & Pavlova & lutheri & B \\
\hline & Isochrysis & galbana, add. galbana “Tahiti” (T-iso) & $\mathrm{B}, \mathrm{GW}$ \\
\hline Dinophyta (dinoflagellates) & Crypthecodinium & cohnii & RAD \\
\hline
\end{tabular}

Key: FFI formulated feed ingredient; B bivalve molluscs (larvae/postlarvae/broodstock), C crustacean larvae (shrimps, lobsters); R rotifer live prey; RAD rotifer and Artemia live prey (dry product form); GU gastropod molluscs and sea urchins; GW "green water" for finfish larvae

Source: Own compilation 
composition, digestibility and absence of toxins or irritants (Muller-Fuega et al. 2003a; Muller-Fuega et al. 2003b; Muller-Fuega et al. 2004; Tredici et al. 2009; Anon. 2010b; Guedes, Malcata 2012).

Table 1 provides a non-exhaustive list of the most commonly used strains and their typical areas of application in aquaculture.

A comprehensive literature exists on the nutritional composition of these and other microalgal strains and their efficacy as aquaculture hatchery feeds (Brown et al. 1997; Muller-Feuga et al. 2003a; Muller-Feuga et al. 2003b; MullerFeuga et al. Becker 2004; Guedes, Malcata 2012).

While scientific studies have demonstrated the ability to manipulate the nutritional composition of individual microalgal strains (e.g., n-3 HUFA content of Nannochloropsis sp., Pal et al. 2011), in practice hatchery operators focus on maintaining uninterrupted supplies of microalgae by avoiding system crashes or culture contamination. Delivery of a balanced diet to the aquaculture species is generally achieved by supplying a mixture of different microalgal strains, guided by typical published nutritional profiles for these strains (e.g., Brown et al. 1997).

\subsection{Methods of Microalgae Cultivation for Aquaculture}

In approximate order of engineering complexity and achievable culture density, the main types of microalgal cultivation system used in aquaculture, all of which are phototrophic, are:

- open ponds or tanks, with or without aeration or stirring;

- bubble or airlift columns, usually oriented vertically, or less frequently horizontally;

- closed photobioreactors (PBRs), most commonly tubular in configuration or less commonly flat panel PBRs.

These methods of microalgal cultivation have been regularly reviewed from an aquaculture standpoint over the past 15 years (Borowitzka 1997; Duerr et al. 1998; Muller-Fuega et al. 2003a; Zmora, Richmond 2004; Tredici et al. 2009). During this period, no major technological step-changes are discernible, although there is a notable trend towards greater adoption of closed PBRs and for semi-con- tinuous or continuous modes of operation, alongside more established batch cultivation techniques. The adoption by aquaculture hatcheries of heterotrophically grown microbial biomass and biomass extracts as partial replacements for live microalgae also represents a significant technological advance during this period (see section 2.3.5).

The types of microalgal production system adopted by aquaculture hatcheries often reflect regional aquaculture preferences, rather than differences in the particular strains or quantities of microalgae required by different aquaculture species. To illustrate, microalgae used to provide green water for marine finfish larviculture (see section 2.3.4) are often produced extensively using outdoor ponds or tanks in South East Asia, whereas European aquaculture hatcheries typically cultivate individual microalgal strains intensively in bubble or airlift columns, or closed PBRs (Shields 2001).

\subsection{Role of Microalgae in Aquaculture Hatcheries}

\subsubsection{Microalgae as a Feed Source for Filter- feeding Aquaculture Species}

It is a common reproductive strategy among marine invertebrates to broadcast high numbers of microscopic larvae into the water column, to ensure widespread distribution of offspring. These planktonic larvae are different in appearance and habit from later developmental stages and undergo a dramatic metamorphosis to the juvenile form. Key examples from aquaculture include bivalve molluscs, decapod crustaceans (shrimps, crabs and lobsters), sea urchins, and polychaete worms.

In many cases, the larvae are filter feeders, relying on microalgae throughout their planktonic phase (e.g., bivalve molluscs, some sea urchins and polychaete worms) or alternatively switching from filter feeding to predating on zooplankton during larval development (e.g., penaeid shrimps). These life history strategies require the aquaculturist to supply microalgae during some, if not all of the hatchery phase. Tredici et al. (2009) provide a recent overview of the typical microalgal strains and feeding strategies used for these groups of aquatic invertebrates. 
For bivalve mollusc production, the obligation to provide microalgae continues into the nursery phase, since bivalves are obligate filter feeders throughout their life history. Bivalve hatcheries therefore tend to possess amongst the highest microalgal production capacity of any form of food aquaculture, with particular attention being paid to hygiene status to avoid crashes or transfer of pathogenic organisms to the shellfish (Aji 2011). Combinations of Bacillariophyte and Prymnesiophyte microalgal strains are the most commonly used feed source for bivalves, both for hatchery/nursery rearing and conditioning of broodstock (Helm et al. 2004).

\subsubsection{Microalgae as a Feed Source for Zooplanktonic Live Prey}

Where larvae of aquaculture species are predatory rather than filter-feeding (e.g., finfish larvae and decapod crustacean larvae) the most common husbandry strategy is to feed with zooplanktonic live prey rather than formulated inert diets. This reflects the technological challenge and high costs of providing nutritionally balanced, digestible feeds in the correct physical form for small planktonic larvae, whose digestive capacity is only partially developed (Conceição et al. 2010).

Thanks to innovations begun in the 1960s, aquaculture hatcheries almost ubiquitously use rotifers (Brachionus sp.) followed by brine shrimp (Artemia sp.) as the key zooplanktonic live prey for larval finfish and decapods (Bengtson 2003). These zooplankton are not the natural prey of the aquaculture species and have suboptimal nutritional composition, however their ease of culture (rapid reproduction rates, high stocking densities) outweighs their nutritional shortcomings in most cases (Lubzens and Zmora 2003; Dhont, Stappen 2003; Conceição et al. 2010). Extensive research and product development has gone into improving rotifer and brine shrimp nutritional quality by manipulating their diet (in particular, to enhance n-3 HUFA content), e.g. by microalgal strain selection or by incorporating dried microalgal biomass into formulated inert diets.

Where the aquaculture species of interest are either too small to accept rotifers as a first prey (e.g., some tropical snappers and groupers), or are prone to nutrition-related developmental abnormalities (e.g., Atlantic halibut), copepods offer a suitable alternative zooplankton (Conceição et al. 2010). However, the lower culture densities achievable for copepods compared to rotifers/Artemia impose practical limitations on supplying them at larger scales of intensive aquaculture production.

Hatchery production of rotifers was initially based on feeding with live microalgae and/ or baker's yeast. Commonly used microalgal strains for this purpose are Nannochloropsis sp., Tetraselmis sp., Pavlova lutheri and Isochrysis galbana (Conceição et al. 2010). Commercial off-the-shelf formulations have been developed and are now widely used as alternatives to live microalgae and yeast. Depending on their specific formulation, these products are intended to optimise growth and reproduction of the rotifers and/or to enhance their final nutritional composition before feeding to larvae. This latter process is widely referred to as "enrichment". Even where hatcheries have adopted such artificial feeds for mass rotifer cultivation, it is common to retain rotifer master cultures on live microalgae, as this simplifies hygiene maintenance and lessens the likelihood of the cultures crashing.

The use of brine shrimp, Artemia sp., in aquaculture is based on supplies of resistant cysts that are commercially collected from hypersaline lakes (Dhont, Stappen 2003). These cysts represent a convenient storable product for aquaculture hatcheries, from which planktonic nauplii can be hatched on demand. Hatcheries do not typically provide live microalgae to these early stages of Artemia, since formulated products have been developed to grow and enrich the nauplii (Dhont, Stappen 2003).

Where copepods are used as an initial prey organism, live microalgae remain the preferred diet for planktonic groups (orders Calanoida and Cyclopoida), whereas benthic copepods (order Harpacticoida) are more amenable to cultivating on inert feeds (Støttrup 2003).

Among the products used as feed for aquaculture live prey are several heterotrophically grown marine microorganisms (Tredici et al. 2009). The first such product to reach the aquaculture market was the DHA-rich fungal thraustochytrid, Schizochytrium, which was initially developed as a hu- 
man nutritional supplement but is also now widely used for aquaculture live prey production/enrichment in powder form. The dinoflagellate, Crypthecodinium cohnii, has been similarly exploited owing to its high DHA content.

\subsubsection{Benthic Microalgae as a Feed Source for Gastropod Molluscs and Echinoderms}

Unlike bivalve molluscs, the larvae of abalone (gastropoda) and some species of sea urchin (echinoidea), do not require microalgae during their planktonic phase, relying instead on internal yolk reserves for energy. This simplifies hatchery rearing procedures (no microalgae required), however, abalone and urchins do initially graze on benthic microalgae (those living on surfaces) when they settle out from the plankton (Heasman, Savva 2007; Azad et al. 2010).

Natural assemblages of benthic diatoms are typically encouraged to grow as a feed source, by pre-exposing artificial substrates or macroalgal germlings to unfiltered seawater, upon which the microalgae grow (Heasman and Savva 2007). This natural colonisation process becomes limiting at higher abalone stocking densities, where the rate of algal growth can be outpaced by grazing (Dyck et al. 2011). The addition of cultured diatoms, such as Navicula sp., Nitzschia sp. and Amphora sp. (Viçose et al. 2012) offers greater control for intensive abalone nurseries, although challenges exist in optimising their methods of cultivation and deployment.

Comparatively few publications exist on appropriate cultivation systems for diatoms. Araya et al. (2010) reported the use of 20L polycarbonate carboys containing PVC filaments for culturing mixed benthic diatom strains, which were administered successfully to postlarval Haliotis rufescens. The same research group have also described a PBR design for diatoms, based on an aerated acrylic cylinder containing a bottle brush-like ar- ray of PVC "bristles" (Silva-Aciares, Riquelme 2008).

\subsubsection{Addition of Microalgae to Fish Larval Rearing Tanks}

The practice of rearing marine finfish larvae in the presence of microalgae is commonplace and is typically, although not exclusively, associated with higher survival and growth rates than when larvae are reared in clear water (Muller-Feuga et al. 2003b; Tredici et al. 2009; Conceição et al. 2010). In the so-called "green water" technique, microalgae and zooplankton are bloomed within ponds or large tanks, into which the fish larvae are stocked. This rearing method can be based on natural microalgal assemblages, which are encouraged to bloom by fertilizer addition (Shields 2001). Alternatively, cultured microalgal strains can be inoculated into rearing tanks for this purpose provided the system water has been pre-treated to exclude competing microorganisms.

The "pseudo-green water" rearing technique relies instead on regular addition of cultured microalgae to the fish larval rearing tanks, to replace that removed by live prey grazing and dilution (water exchange; see fig. 1). This approach is required to sustain the higher larval stocking densities that are typical in most commercial marine fish hatcheries

Fig. 1: Addition of live microalgae to a fish larval rearing tank - "pseudo-green water" technique

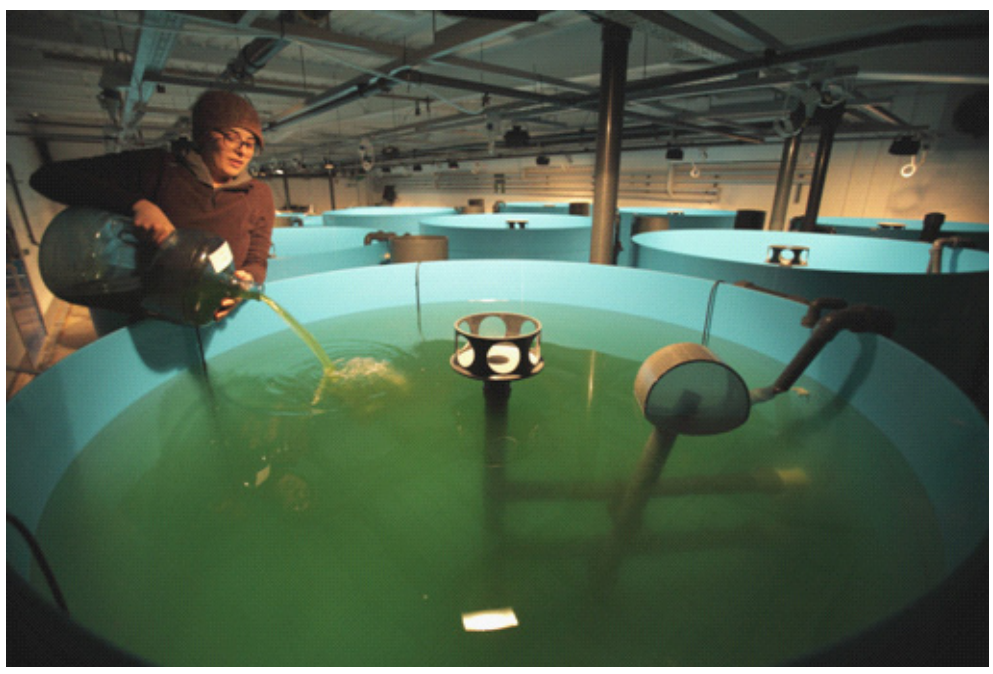

Source: Centre for Sustainable Aquatic Research, Swansea University 
in Europe and North America. Commonly used microalgal strains for this purpose are Nannochloropsis sp., Isochrysis sp. and Tetraselmis sp.

Given that few groups of fish are equipped to feed directly on microalgae (Muller-Feuga et al. 2003b), extensive research effort has been applied to understand the mechanisms by which microalgae enable superior rearing performance of larval fish and to optimise their delivery in aquaculture hatcheries (Conceição et al. 2010). This research encompasses the effects of microalgae on:

- nutritional status of live prey and fish larvae;

- fish larval behaviour, particularly feeding behaviour;

- larval digestive function;

- microbial community composition in the rearing water and the larval digestive tract.

A range of effects have been reported across different microalgal strains, fish species, experimental conditions and observational/analytical techniques (reviews by Muller-Feuga et al. 2003b; Conceição et al. 2010). These include evidence for:

- improved chemical water quality in the presence of microalgae;

- greater larval absorption of soluble organics from the rearing water;

- direct ingestion of microalgal cells (passive and active) by larvae;

- improved visual contrast between prey and background;

- enhanced prey capture rates and greater gut fullness;

- stimulation of larval digestive enzyme production;

- more diverse microflora in rearing water and in the larval digestive tract.

Recent research by Natrah et al. (2011) suggests that microbial conditioning by microalgae may extend to impeding cell-to-cell signalling (quorum sensing) by bacterial pathogens. In a laboratory screening study focused on microalgal strains commonly used in aquaculture, several of the tested strains interrupted signalling by pathogenic Vibrio harveyii, leading the authors to postulate that such microalgae offer potential as aquaculture biocontrol agents. A logical extension of this research would be to challenge fish larvae with pathogens in the presence/absence of those microalgae that showed bioactivity during screening.

\subsubsection{Use of Microalgal Concentrates in Aquaculture Hatcheries}

Commercially available concentrates offer a convenient source of microalgae for aquaculture hatcheries. This area of microalgal product development has recently been reviewed by Tredici et al. (2009), including the technologies involved in concentrating and stabilising microalgae and descriptions of a range of commercially available products, with prices.

The practice of concentrating live microalgae originated for local use within individual hatcheries, typically using disk-stack centrifuges or membrane filters (Molina Grima et al. 2003). This practice is still used in some large hatcheries, although commercial concentrates have become widely adopted.

From an aquaculture hatchery perspective, the key desired attributes for microalgal concentrates are:

- high cell concentration without damage to cells;

- suitable nutritional composition;

- acceptable shelf life (maintain nutritional quality, avoid spoilage) using standard cold storage methods, avoiding the use of preservatives that would be harmful to live prey or larvae;

- hygienic and free from pathogens;

- avoidance of clumping and easy to suspend uniformly in water;

- regularly available and affordable.

Two main categories of product have emerged: firstly, concentrates of those microalgal strains that are particularly favoured for aquaculture and, secondly, industrial biotechnology strains, such as heterotrophically produced Chlorella sp., that are available at higher volume/lower price but have a more limited scope of application, such as in the production of live prey.

Many of the key microalgal strains referred to in table 1 are now available as concentrates (Tredici et al. 2009). These are frequently marketed as total replacements for live microalgae although, in practice, they usually serve as a 
backup or supplement to live microalgae produced in-house. This reflects both high purchase costs of the concentrates and generally inferior rearing performance when compared to live microalgae, as previously reported across diverse aquaculture species and areas of hatchery deployment (Muller-Feuga et al. 2003b; Tredici et al. 2009; Conceição et al. 2010).

That is not to underplay the value of such concentrates in providing backup against crashes or out-of-season shortages and in enabling smaller enterprises to operate without an in-house microalgal production capacity. However, as referred to in previous reviews, lower unit cost and performance more on a par with live microalgae will be needed to facilitate market expansion within the commercial aquaculture sector.

The performance discrepancy between concentrated and live microalgae is less marked in the area of live prey production, where industrially produced Chlorella is now routinely used for rotifer production, competing in the market with other forms of dry feed (Tredici et al. 2009).

\section{Use of Algae in Formulated Feeds for Aquaculture Species and Terrestrial Livestock}

Quite a number of animal nutrition studies as to the "super food" status of algae have been publicized and reviewed and the challenge remains to support the claims being made by scientifically based evidence. Results from experimental studies can be difficult to interpret, as several compounds in algae can have confounding effects. Even when used at small amounts in livestock and aquaculture feeds, algae have been credited with improving immune system (Turner et al. 2002), lipid metabolism (Nakagawa 1997; Güroy et al. 2011), antiviral and antibacterial action, improved gut function (Michiels et al. 2011), stress resistance (Nath et al. 2012; Sheikhzadeh et al. 2012) besides providing a source of protein, amino acids, fatty acids, vitamins and minerals, and other biologically active phytochemicals (Pulz, Gross 2004; Becker 2004, Gouveia et al. 2008).

Nutritional studies evaluating algae as a major feed ingredient for farmed animals are currently fewer in number, due to the large amounts of biomass needed. Thus, in most studies to date, the algal biomass/extracts from algae are not considered as an essential feed source, but rather as enhancing "standard" feed formulations.

\subsection{As a Supplement to Enhance the Nutritional Value of Formulated Feeds}

\subsubsection{Vitamins and Minerals}

In the view of consumers, the concept of sustainable, "chemical free" and organic farming has become very appealing, including using the natural forms of vitamins and minerals instead of the synthetically produced ones. Both micro- and macroalgae have potential as mineral additives to replace the inorganic mineral salts that are most commonly used in the animal feed industry. It has been suggested that the natural forms are more bio-available to the animal than the synthetic forms and can be even altered or manipulated via the process of bio-absorption (Doucha et al. 2009).

Mineral rich seaweed has been incorporated in commercial salmon feeds at $15 \%$ in lieu of manufactured vitamin and mineral pre-mixes (Kraan, Mair 2010). Final tests suggested that salmon fed the "seaweed" feeds appeared to be healthier, more active; flavour and texture were improved which may have been due to the bromophenolic compounds found in seaweeds. Elsewhere, Enteromorpha prolifera and Cladophora sp., when added to the feeds of laying hens, positively influenced egg weight and egg shell thickness (Michalak et al. 2010).

The vitamin content of algal biomass can vary significantly among species. Ascorbic acid shows the greatest variability according to Brown and Miller (1992), although this may have been due to differences in processing, drying and storage of algae, as ascorbic acid is very sensitive to heat. This highlights the drawback of supplying essential micronutrients via natural sources, i.e. there is too much variability arising from the combined effects of different algal species, growing season, culture conditions, and processing methods to reliably supply the required micronutrients in a pre-determined fashion. Accordingly, algal biomass mainly offers a supplementary source rather than a complete replacement for manufactured minerals or vitamins in animal feeds. 


\subsubsection{Pigments}

The carotenoids are a class of yellow, orange or red naturally occurring pigments, which are distributed everywhere in the living world. Only the microorganisms, fungi, algae, and higher plants are able to synthesise carotenoids de novo, therefore animals rely on the pigment or closely related precursor being supplied in their diets, which in nature would have passed on through the food chain.

Farmed salmonid fish therefore require supplementation of dietary astaxanthin to achieve the pink colour of the fillet. Synthetic carotenoids are mainly used for this purpose in commercial aquaculture, although algae-derived carotenoids can also impart pigmentation effectively (Soler-Vila et al. 2009; Choubert, Heinrich 1993). Astaxanthin obtained from Haematococcus pluvialis has been approved as a colour additive NatuRose ${ }^{\circledR}$ - in salmon feeds and is typically used for organically certified salmon production.

Aside from salmonids, most species of farmed fish display pigmentation of the skin rather than the flesh, which contributes to their attractive appearance and thus satisfies customer demand.

$H$. pluvialis has been shown to be successful in enhancing the reddish skin colouration of red porgy, Pagrus pagrus (Chatzifotis et al. 2011) and also of the penaeid shrimp, Litopenaeus vannamei (Parisenti et al. 2011). Both natural and synthetic sources of carotenoids have been successfully used to augment the yellow skin colouration in gilthead sea bream (Gomes et al. 2002; Gouveia et al. 2002). Chlorella sp. and Spirulina sp. are commonly incorporated into feeds for ornamental fish, where colouration and healthy appearance is the main market criterion (Zatkova et al. 2011; Sergejevová, Masojídek 2011; Gouveia, Rema 2005).

Seaweeds are the preferred feed of sea urchins in nature and in an aquaculture setting, carotenoid-rich sources such as Ulva sp. and Gracilaria sp. are necessary to enhance the orange colour of the gonads that consumers prefer (Shpigel et al. 2005).

For pigmentation of broilers and egg yolk, formulated feeds traditionally contain dehydrated alfalfa meal and/or corn, both of which are rich sources of lutein and zeaxanthin. Seaweed biomass has been reported to increase the pig- mentation of egg yolk when used at a dietary inclusion level of $15 \%$ (Strand et al. 1998). Gouveia et al. 1996 reported that Chlorella vulgaris biomass produced yolk pigmentation comparable to other commercially used pigments. Chlorella is not only credited with improving the health status of laying hens but also with improving egg quality and pigmentation (Halle et al. 2009). According to Waldenstedt et al. (2003), H. pluvialis also has good potential as a natural pigment enhancer in broiler chickens.

\subsubsection{Fatty Acids}

Farmed fish and shellfish offer rich sources of long chain, highly unsaturated fatty acids (HUFA), due to the inclusion of fish meal and fish oil in formulated aquafeeds. HUFA are crucial to human health and play an important role in the prevention and treatment of coronary heart disease, hypertension, diabetes, arthritis, and other inflammatory and autoimmune disorders. Due to the global shortage of fish oil and fish meal, researchers are looking increasingly into alternative sources of lipid, including from algal biomass.

Unlike terrestrial crops, algae can directly produce HUFA such as arachidonic acid (AA, 20:4n-6) (Porphyridium), eicosapentaenoic acid (EPA, 20:5n-3) (Nannochloropsis, Phaeodactylum, Nitzschia, Isochrysis, Diacronema) and docosahexaenoic acid (DHA, 22:6n-3) (Crypthecodinium, Schizochytrium). Whilst most of these algae are not suitable for direct human consumption, they might indirectly boost their nutritional value for humans if added to animal feeds. However, relatively few studies have been carried out to date to evaluate microalgal lipids in feeds for farmed fish (Atalah et al. 2007; Ganuza et al. 2008).

Despite the typically low lipid content of seaweeds, Dantagnan et al. (2009) reported that Macrocystis pyrifera meal enhanced the level of PUFAs in trout flesh, when included in the diet at a level of $6 \%$. Micro- and macroalgae have similarly been tested as alternatives to fish oil and flax seed for boosting the HUFA content of hens' eggs (Carrillo et al. 2008; Kassis et al. 2010). 
Table 2: Typical composition of formulated feeds for livestock and several species of commercial fish (on as fed basis) and feed/gain ratio

\begin{tabular}{lccccc}
\hline & $\begin{array}{c}\text { \% Crude } \\
\text { Protein }\end{array}$ & $\begin{array}{c}\text { \% Crude } \\
\text { Lipid }\end{array}$ & $\begin{array}{c}\text { \% Crude } \\
\text { Carbohydrate }\end{array}$ & $\begin{array}{c}\text { Metabolisable Energy } \\
\text { MJ/kg }\end{array}$ & FCR $^{*}$ \\
\hline Poultry & 21.0 & 5.0 & 60 & 13.0 & \\
Pigs & 16.0 & 5.0 & 60 & 12.5 & 2.2 \\
Cattle & 12.0 & 4.0 & 65 & 10.1 & 3.0 \\
Salmon & 37.0 & 32.0 & 15 & 21.0 & 1.0 \\
Sea bream & 45.0 & 20.0 & 20 & 19.1 & 1.6 \\
Tilapia & 35.0 & 6.0 & 40 & 13.5 & 1.5 \\
Shrimp & 35.0 & 6.0 & 40 & 13.5 & 2.0 \\
\hline
\end{tabular}

* Feed conversion ratio $=$ feed consumed $($ dry $) /$ live weight gain

Source: Own compilation

\subsection{As a Potential Feed Ingredient - Source of Protein and Energy}

In both aquaculture and agriculture, producers commonly rely on formulated feeds to ensure optimal growth, health and quality of the farmed animal. Given the economic importance of feeds and feeding, nutritionists therefore need to develop nutritionally balanced diets using commonly available raw ingredients. Once there is reliable data on the nutrient and energy requirements of the target species for a given production performance, specific feeds can be formulated and feeding regimen established.

Typical compositions of feed and feed/gain ratio are summarised in table 2 for several farmed terrestrial and aquatic animal species. This table just provides an overview, as different feed formulations are used depending on the production stage of the target species. Since protein is generally one of the most expensive feed ingredients, targeted rations are used and the amounts of protein in the diet are reduced as the animals grow. As can be seen, feeds for aquatic animals are more energy and nutrient dense than those for terrestrial animals. Due to this, fish need to be fed less to support each unit of growth, as is indicated by the lower feed conversion ratio (FCR).

Traditionally, fish meal and fish oil have been a substantial component of feeds at least in aquaculture, however this source is finite. With fish meal and fish oil prices increasing, there has been a growing interest in partial or complete replacement of fish meal by alternative protein sources of either animal or plant origin. Raw materials other than fish meal are selected for their nutritive value, balance of amino acids, digestibility of proteins, lipids and quality of fatty acids, absence of anti-nutritional factors, availability and cost and lipid rich algae biomass is being considered as one of the alternative ingredients of the future (Lupatsch 2009).

To help in assessing algae as a potential source of protein and energy in the form of carbohydrates and lipids, table 3 compares the typical nutritional profiles of commercially available animal feed ingredients with some selected micro- and macroalgae.

In addition to quantifying the gross composition of feed ingredients, knowledge of their digestibility is needed in order to assess the nutritional value. Digestibility trials are usually carried out in vivo by adding an indigestible marker to the feed at a known amount, collecting faecal matter by a suitable method and analysing the ratio between nutrient and marker in the faecal matter. Very few of the required digestibility trials have been completed with micro- or macroalgal biomass to date, partly due to the limited availability of material. A digestibility trial with carnivorous mink, a model used for salmon and other farmed monogastric species, was recently reported by Skrede et al. (2011). Three microalgae, Nannochloropsis oceanica, Phaeodactylum tricornutum and Isochrysis galbana, were included at graded levels up to $24 \%$ (dry weight) in the feed. The protein digestibilities determined by linear regression for $N$. oceanica, $P$. tricornutum and I. galbana were found to be 35.5, 79.9 and $18.8 \%$, respectively. The algae used had been freeze dried prior to the trial and the authors hypothesised that the cell wall of the diatom P. tricornutum may have been more easily broken down by digestive processes than the others. 
Table 3: Typical composition of commercially available feed ingredients and algae species (per dry matter)

\begin{tabular}{|c|c|c|c|c|c|}
\hline & $\begin{array}{l}\text { \% Crude } \\
\text { Protein }\end{array}$ & $\begin{array}{l}\text { \% Crude } \\
\text { Lipid }\end{array}$ & $\begin{array}{c}\% \text { Crude } \\
\text { Carbohydrate* }\end{array}$ & $\% A s h$ & $\begin{array}{c}\text { Gross Energy } \\
M J / k g\end{array}$ \\
\hline Fish meal & 63.0 & 11.0 & - & 15.8 & 20.1 \\
\hline Poultry meal & 58.0 & 11.3 & - & 18.9 & 19.1 \\
\hline Corn-gluten & 62.0 & 5.0 & 18.5 & 4.8 & 21.3 \\
\hline Soybean & 44.0 & 2.2 & 39.0 & 6.1 & 18.2 \\
\hline Wheat meal & 12.2 & 2.9 & 69.0 & 1.6 & 16.8 \\
\hline Spirulina & 58.0 & 11.6 & 10.8 & 13.4 & 20.1 \\
\hline Chlorella & 52.0 & 7.5 & 24.3 & 8.2 & 19.3 \\
\hline Tetraselmis & 27.2 & 14.0 & 45.4 & 11.5 & 18.0 \\
\hline Gracilaria $\mathrm{sp}^{1}$ & 34.0 & 1.5 & 37.1 & 26.9 & 13.4 \\
\hline Gracilaria $\mathrm{sp}^{2}$ & 10.0 & 0.9 & 50.1 & 34.0 & 11.2 \\
\hline Ulva lactuca $^{1}$ & 37.4 & 2.8 & 42.2 & 17.4 & 15.7 \\
\hline Ulva lactuca $^{2}$ & 12.5 & 1.0 & 57.0 & 24.5 & 11.2 \\
\hline Schizochytrium $^{3}$ & 12.5 & 40.2 & 38.9 & 8.4 & 25.6 \\
\hline
\end{tabular}

* Carbohydrates calculated as the difference $\% \mathrm{DM}-(\%$ protein $+\%$ lipid $+\%$ ash $)$

${ }^{1}$ Cultured in effluent of fish tanks

${ }^{2}$ Collected from natural habitat

${ }^{3}$ Commercial product, Martek Biosciences

Source: Own compilation/analyses performed by authors

The potential effects of algal cell wall structure on digestibility to humans and non-ruminant animals has been raised by several authors, as reviewed by Becker (2004). Janczyk et al. (2007) tested the digestibility of Chlorella biomass in rats using three treatments such as spray-dried, spray-dried and electroporated and spray-dried and ultrasonicated. Ultrasonication was found to increase the protein digestibility of Chlorella from $53 \%$ (spray-dried) to $63 \%$.

Digestibility coefficient of solar dried Spirulina biomass has been tested for Arctic char and Atlantic salmon at $30 \%$ dietary inclusion level (Burr et al. 2011). Protein digestibility ranged between $82 \%$ and $84.7 \%$ for the two fish species respectively. These relatively high digestibility coefficients compare favourably with terrestrial plant ingredients, confirming the high potential of Spirulina as a protein source for farmed fish.

The digestibility of "DHA-Biomeal", a byproduct from DHA-rich Schizochytrium after de-lipidation, has been assessed for gilthead sea bream (Lupatsch, unpublished data). The composition of the dry DHA-Biomeal was determined as $6 \%$ protein, $9 \%$ lipid and approximately $70 \%$ carbohydrates including fibre. At $6 \%$, protein content was too low to be considered as a significant source of amino acids and overall energy digestibility was found to be only $64 \%$, placing DHABiomeal in the same category as a carbohydrate-rich ingredient such as whole wheat or corn meal. A possible means of increasing the nutritional value of algal ingredients such as DHA-Biomeal would be to break down the cell wall fragments by mechanical treatment, or even by removal of most of the fibre, although such processing steps may be prohibitively expensive.

In addition to digestibility measurements, in vivo growth trials need to be carried out in which the novel feed ingredient is supplied in sufficient amounts (see fig. 2). Even with seemingly nutritionally adequate diets, poor weight gain may be encountered in practice, because of low palatability of the test ingredient and therefore reduced feed intake. Coutinho et al. (2006) found that supplementing feeds for goldfish fry with freeze dried biomass of Isochrysis galbana, as a substitute for fish meal protein, had a negative effect on growth and survival (Coutinho et al. 2006). Aside from the question of palatability, one of the reasons may have been that the feeds were not iso-nitrogenous: dietary protein levels decreased with increasing algae inclusion level and it is known that protein is a limiting factor, especially in the small fast growing larval stages.

In contrast, Nandeesha et al. (2001) reported improved growth rates for Indian carp fry with increasing levels of Spirulina platensis in feeds. Palmegiano et al. (2005) reported that sturgeon fed Spirulina-based feeds even outperformed 
Fig. 2: Experimental fish feeds containing different proportions of dried Chlorella in substitution for fish meal

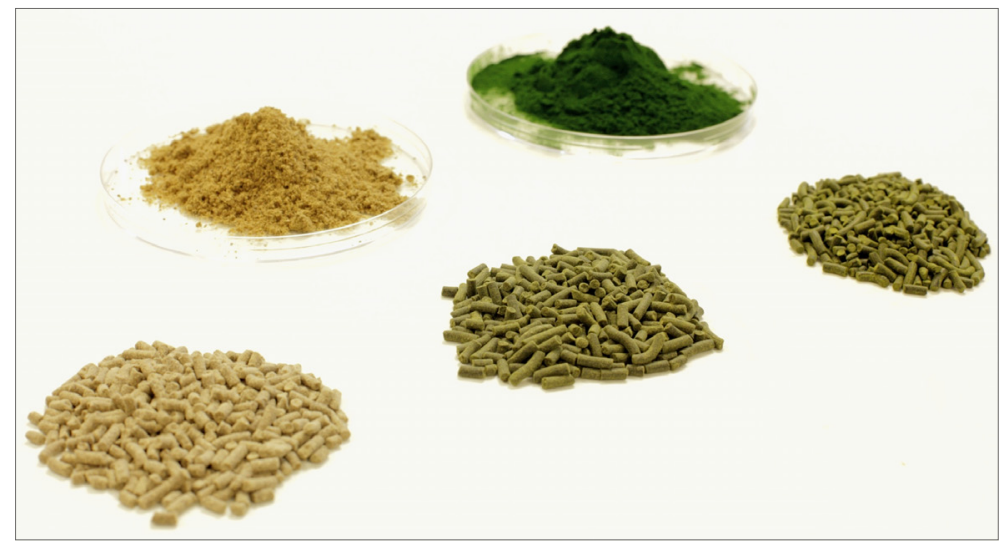

Source: Centre for Sustainable Aquatic Research, Swansea University to efficiently digest the carbohydrate fraction of Chlorella $s p$. and Scenedesmus sp., although this poor performance may have been due to the specific characteristics of these algal strains.

As noted above, the costs of fish meal and fish oil are steadily increasing. Thus, if a source of protein-rich or lipid-rich algal meal came onto the market at an affordable price, the animal feed industry would certainly consider using it based on existing evidence of the nutritional value of algal biomass. However, as those receiving fish meal-based diets. Contradictory results were reported by Olvera-Novoa et al. (1998), where Spirulina-supplemented feeds depressed growth performance of tilapia fry. A more recent study by Walker and Berlinsky (2011) tested the nutritional value of a Nannochloropsis sp. and Isochrysis sp. mix for juvenile Atlantic cod. The authors described decreased feed intake and subsequently reduced growth with increasing algae inclusion. They concluded that reduced palatability of the algal meal caused the deterioration in cod growth.

Valente et al. (2006) recommended that macroalgae such as Gracilaria and Ulva can be incorporated up to $10 \%$ in European sea bass feeds without affecting the performance of fish. Other studies using seaweed have suggested that kelp meal works as an excellent additive (attractant, agglutinant and binder) in pelleted feeds for penaeid shrimps and thus improved feed utilisation efficiency in this slow feeding species (Cruz-Suarez et al. 2009; Silva-Neto et al. 2012).

Based on the known structural and compositional characteristics of algal biomass, it should be expected that ruminants are among the most suitable recipients, since they ought to be able to break down even unprocessed algal cell walls due to their unique digestive system. Performance parameters of lambs when fed $U$. lactuca all indicated that seaweed could be categorised as a low-energy high-nitrogen feedstuff in ruminants (Arieli et al. 1993). Conversely, an earlier study by Hintz et al. (1966) concluded that ruminants are unable shown in table 4 , all categories of algal products are currently much higher in cost than the commodity feedstuffs used in animal feeds. One also has to consider the unit price of protein or lipid. To illustrate, a protein source such as soybean meal only contains $45 \%$ protein but also a significant amount of indigestible bulk. Soy protein concentrates with up to $70 \%$ protein are available but this process renders them more expensive. Of the algal products listed in table 4, Gracilaria is lowest in price; however, the price per unit of protein is still excessively high when compared to existing commodity feedstuffs that contain much higher protein content.

\section{Outlook}

Microalgae cultivation has been integral to modern forms of aquaculture for more than 40 years, developing and expanding alongside the "microalgae-for-food" and "microalgae-for-fuels" sectors. During this period, aquaculturists have devised robust methods for culturing a diverse range of phototrophic microalgal strains with high nutritional value, that are more susceptible to crashes and contamination than those extremophiles that are mass cultured for other purposes in open ponds or raceways (e.g., Arthrospira sp., Dunaliella sp., Haematococcus sp.).

This aquaculture skills base and associated technologies (e.g., affordable closed PBRs) for culturing "sensitive" microalgal strains adds value to the current microalgal biotechnology agenda of 
Table 4: Global prices of ingredients used in animal feeds compared to currently available algal products

\begin{tabular}{|c|c|c|}
\hline Ingredient & Main use & Price 2011 (€/ton dry) \\
\hline Fish meal $^{1}$ & Feed & 1,091 \\
\hline Soybean meal ${ }^{1}$ & Feed & 254 \\
\hline Rapeseed oil ${ }^{1}$ & Food & 941 \\
\hline Wheat $^{1}$ & Feed & 212 \\
\hline Fish oil ${ }^{2}$ & Feed & $985-1,360$ \\
\hline Tetraselmis $^{3}$ & Bivalve shellfish & $190,000-270,000$ \\
\hline Spirulina $\mathrm{sp}^{4}$ & Health food & $7,500-14,000$ \\
\hline Chlorella sp ${ }^{4}$ & Health food & $34,000-45,000$ \\
\hline Gracilaria $\mathrm{sp}^{4}$ & Agar, feed & $378-756$ \\
\hline Laminaria - Kelp sundried ${ }^{4}$ & Food & $1,590-1,890$ \\
\hline
\end{tabular}

http://www.indexmundi.com

http://www.globefish.org

http://www.reed-mariculture.com

http://www.alibaba.com

Source: Own compilation

biofuels and high value biomass extracts through integrated biorefinery. It is expected that benefits will return to the aquaculture sector through current biotechnology investments, in the form of more efficient microalgal production systems and greater availability of high quality microalgal biomass and extracts for use as hatchery feeds, etc. This is already illustrated by the adoption of heterotrophically produced microbial biomass (Schizochytrium sp., Crypthecodinium cohnii) as hatchery feeds; more abundant and cheaper feed products can be expected in future, provided the current aspirations of microalgal biotechnologists are realised.

Whether algal biomass will be adopted in future as a bulk feedstuff to supply protein and energy in animal feeds, or will remain only as a supplement, will depend on biomass availability, composition and cost. As referred to in Section 3.2 , there is currently a large discrepancy in the global supply and purchase cost of algal biomass versus existing commodity animal feedstuffs, even for those categories of algal product that are produced at the largest scale. We conclude that until supplies increase and costs decrease, algal biomass and biomass extracts will continue to occupy niche markets within the animal feed sector, such as sources of pigments. The current global drive to produce biofuels from algae offers a key opportunity to shift existing biomass supply and cost structures in favour of animal feeds, within an integrated biorefinery.

Assuming sufficient quantities of algal biomass do become available at a suitable price, algae producers and animal feed manufacturers will still need to take into account the potentially large variations in proximate composition (proteins, lipids, fatty acids, minerals, etc.) and digestibility encountered among different algal strains and growing conditions. Effort is needed to ensure a more consistent composition of algal biomass, so that manufacturers can readily incorporate this new feedstuff alongside existing ingredients in formulated feeds. To improve their digestibility, some types of algal biomass may require additional processing steps (over and above those applied to conventional feedstuffs), that add further to their cost.

Although there are examples of macroalgal species containing relatively high levels of protein or lipid, it seems likely that microalgae will provide the most suitable bulk feedstuffs for use in finfish diets, whereas macroalgae may be more suitable for use with terrestrial livestock and with lower trophic level aquaculture species.

\section{References}

Aji, L.P., 2011: The Use of Algae Concentrates, Dried Algae and Algae Substitutes to Feed Bivalves. In: Makara of Science Series 15/1 (2011), pp. 1-8

Anon., 2010a: The State of World Aquaculture and Fisheries. FAO - Food and Agriculture Organization of the United Nations, Fisheries and Aquaculture Department Anon., 2010b: Report on Biology and Biotechnology of Algae with Indication of Criteria for Strain Selection. In: Report of the AquaFUELS FP7 project, deliverable 1.4.; http://www.aquafuels.eu/ attachments/079_D\%201.4\%20Biology\%20Biotechnology.pdf (download 2.7.12)

Araya, R.; Bahamondes, C.; Barahona, K. et al., 2010: Application of Multi-specific Microalgae Biofilm for Optimization of the Larvae Settlement and Growth of Abalone (Haliotis rufescens) in a Commercial Hatchery. In: Revista de Biología Marina y Oceanografía 45/1 (2010), pp. 59-69 (in Spanish) 
Arieli, A.; Sklan, D.; Kissil, G., 1993: A Note on the Nutritive Value of Ulva lactuca for Ruminants. In: Animal Production 57/2 (1993), pp. 329-331

Atalah, E.; Hernández Cruz, C.M.; Izquierdo, M.S. et al., 2007: Two Microalgae Crypthecodinium cohnii and Phaeodactylum tricornutum as Alternative Source of Essential Fatty Acids in Starter Feeds for Sea Bream (Sparus aurata). In: Aquaculture 270/1-4 (2007), pp. 178-185

Azad, A.K.; McKinley, S.; Pearce, C.M., 2010: Factors Influencing the Growth and Survival of Larval and Juvenile Echinoids. In: Reviews in Aquaculture 2/3 (2010), pp. 121-137

Becker, W., 2004: Microalgae for Aquaculture: The Nutritional Value of Microalgae for Aquaculture. In: Richmond, A. (eds.): Handbook of Microalgal Culture: Biotechnology and Applied Phycology. Oxford, pp. 380-391

Bengtson, D.A., 2003: Status of Marine Aquaculture in Relation to Live Prey: Past, Present and Future. In: Støttrup, J.G.; McEvoy, L.A. (eds.): Live Feeds in Marine Aquaculture. Oxford, pp. 1-16

Borowitzka, M.A., 1997: Microalgae for Aquaculture: Opportunities and Constraints. In: Journal of Applied Phycology 9/5 (1997), pp. 393-401

Brown, M.R.; Jeffery, S.W.; Volkman, J.K. et al., 1997: Nutritional Properties of Microalgae for Mariculture. In: Aquaculture 151/1-4 (1997), pp. 315-331

Brown, M.R.; Miller, K.A., 1992: The Ascorbic Acid Content of Eleven Species of Microalgae Used in Mariculture. In: Journal of Applied Phycology 4/3 (1992), pp. 205-215

Burr, G.S.; Barrows, F.T.; Gaylord, G. et al., 2011: Apparent Digestibility of Macronutrients and Phosphorus in Plant Derived Ingredients for Atlantic Salmon, Salmo salar and Arctic Charr, Salvelinus alpinus. In: Aquaculture Nutrition 17/5 (2011), pp. 570-577

Carrillo, S.; López, E.; Casas, M.M. et al., 2008: Potential Use of Seaweeds in the Laying Hen Ration to Improve the Quality of n-3 Fatty Acid Enriched Eggs. In: Journal of Applied Phycology 20/5 (2008), pp. 721-728 Chatzifotis, S.; vaz Juan, I.; Kyriazi, P.; Divanach, P.; Pavlidis, M., 2011: Dietary Carotenoids and Skin Melanin Content Influence the Coloration of Farmed Red Porgy Pagrus pagrus. In: Aquaculture Nutrition 17/2 (2011), pp. e90-e100

Choubert, G.; Heinrich, O., 1993: Carotenoid Pigments of the Green Alga Haematococcus pluvialis: Assay on Rainbow Trout, Oncorhynchus mykiss, Pigmentation in Comparison with Synthetic Astaxanthin and Canthaxanthin. In: Aquaculture 112/2-3 (1993), pp. 217-226
Conceição, L.E.C. de; Yúfera, M.; Makridis, P. et al., 2010: Live Feeds for Early Stages of Fish Rearing. In: Aquaculture Research 41/5 (2010), pp. 613-640

Coutinho, P.; Rema, P.; Otero, A. et al., 2006: Use of Biomass of the Marine Microalga Isochrysis galbana in the Nutrition of Goldfish (Carassius auratus) Larvae as Source of Protein and Vitamins. In: Aquaculture Research 37/8 (2006), pp. 793-798

Cruz-Suarez, L.E.; Tapia-Salazar, M.; Nietao-Lopez, M.G. et al., 2009: A Review of the Effects of Macroalgae in Shrimp Feeds and in Co-Culture. Comparison of Ulva and Kelps in shrimp feeds. In: Aquaculture Nutrition 15 (2009), pp. 421-430

Dantagnan, P.; Hernandez, A.; Borquez, A. et al., 2009: Inclusion of Macroalgae Meal (Macrocystis pyrifera) as Feed Ingredient for Rainbow Trout (Oncorhynchus mykiss): Effect on Flesh Fatty Acid Composition. In: Aquaculture Research 41/1 (2009), pp. 87-94

Dhont, J.; Stappen, G. van, 2003: Biology, Tank Production and Nutritional Value of Artemia. In: Støttrup, J.G.; McEvoy, L.A. (eds.): Live Feeds in Marine Aquaculture. Oxford, pp. 65-121

Doucha, J.; Livanský, K.; Kotrbáček, V. et al., 2009: Production of Chlorella Biomass Enriched by Selenium and Its Use in Animal Nutrition: A Review. In: Applied Microbiology and Biotechnology 83/6 (2009), pp. 1001-1008

Duerr, E.O.; Molnar, A.; Sato, V., 1998: Cultured Microalgae as Aquaculture Feeds. In: Journal of Marine Biotechnology 6/2 (1998), pp. 65-70

Dyck, M.; Roberts, R.; Jeff, A., 2011: Assessing Alternative Grazing-tolerant Algae for Nursery Culture of Abalone, Haliotis iris. In: Aquaculture 320/1-2 (2011), pp. 62-68

Ganuza, E.; Benitez-Santana, T.; Atalah, E. et al., 2008: Crypthecodinium cohnii and Schizochytrium sp. as Potential Substitutes to Fisheries-derived Oils from Sea Bream (Sparus aurata) Microdiets. In: Aquaculture 277/1-2 (2008), pp. 109-116

Gomes, E.; Dias, J.; Silva, P. et al., 2002: Utilization of Natural and Synthetic Sources of Carotenoids in the Skin Pigmentation of Gilthead Sea Bream (Sparus aurata). In: European Food Research and Technology 214/4 (2002), pp. 287-293

Gouveia, L.; Choubert, G.; Gomes, E. et al., 2002: Pigmentation of Gilthead Sea Bream, Sparus aurata, Using Chlorella vulgaris (Chlorophyta, Volvocales) Microalga. In: Aquaculture Research 33/12 (2002), pp. 987-993 Gouveia, L.; Rema, P., 2005: Effect of Microalgal Biomass Concentration and Temperature on Ornamental Goldfish (Carassius auratus) Skin Pigmentation. In: Aquaculture Nutrition 11/1 (2005), pp. 19-23 
Gouveia, L.; Veloso, V.; Reis, A. et al., 1996: Chlorella vulgaris Used to Colour Egg Yolk. In: Journal of the Science of Food and Agriculture 70/2 (1996), pp. 167-172 Gouveia,L.; Batista, A.P.; Sousa, I. et al., 2008: Microalgae in Novel Food Products. In: Papadopoulos, K.N. (ed.): Food Chemistry Research Developments. Hauppauge, NY, pp. 1-37

Guedes, A.C.; Malcata, F.X., 2012: Nutritional Value and Uses of Microalgae in Aquaculture. In: Muchlisin, Z.A. (ed.): Aquaculture; doi: 10.5772/1516, pp. 59-78

Güroy, D.; Güroy, B.; Merrifield, D.L. et al., 2011: Effect of Dietary Ulva and Spirulina on Weight Loss and Body Composition of Rainbow Trout, Oncorhynchus mykiss (Walbaum), During a Starvation Period. In: Journal of Animal Physiology and Nutrition 95/3 (2011), pp. 320-327

Halle, I.; Janczyk, P.; Freyer, G. et al., 2009: Effect of Microalgae Chlorella vulgaris on Laying Hen Performance. In: Archiva Zootechnica 12/2 (2009), pp. 5-13

Heasman, M.; Savva, N., 2007: Manual for Intensive Hatchery Production of Abalone. NSW Department of Primary Industries

Helm, M.M.; Bourne, N.; Lovatelli, A., 2004: Hatchery Culture of Bivalves: A Practical Manual. In: FAO - FAO - Food and Agriculture Organization of the United Nations, Fisheries Technical Paper 471 (2004)

Hintz, H.F.; Heitmann, H.; Weird, W.C. et al., 1966: Nutritive Value of Algae Grown on Sewage. In: Journal of Animal Science 25/3 (1966), pp. 675-681

Janczyk, P.; Franke, H.; Souffrant, W.B., 2007: Nutritional Value of Chlorella vulgaris: Effects of Ultrasonication and Electroporation on Digestibility in Rats. In: Animal Feed Science and Technology 132/1-2 (2007), pp. 163-169

Kassis, N.M.; Beamer, S.K.; Matak, K.E. et al., 2010: Nutritional Composition of Novel Nutraceutical Egg products Developed with Omega-3-rich Oils. In: LWT - Food Science and Technology 43/8 (2010), pp. 1204-1212

Kraan, S.; Mair, C., 2010: Seaweeds as Ingredients in Aquatic Feeds. In: International Aquafeed 13/6 (2010), pp. 10-14

Lubzens, E.; Zmora, O., 2003: Production and Nutritional Value of rotifers. In: Støttrup, J.G.; McEvoy, L.A. (eds.): Live Feeds in Marine Aquaculture. Oxford, pp 17-64

Lupatsch, I., 2009. Quantifying Nutritional Requirements in Aquaculture - The Factorial Approach. In: Burnell, G.; Allan, G. (eds.): New Technologies in Aquaculture: Improving Production Efficiency, Quality and Environmental Management. Cambridge, pp. 417-439
Michalak, I.; Chojnacka, K.; Dobrzański, Z.; et al., 2011: Effect of Macroalgae Enriched with Microelements on Egg Quality Parameters and Mineral Content of Eggs, Eggshell, Blood, Feathers and Droppings. In: Journal of Animal Physiology and Nutrition 95/3 (2011), pp. 374-387

Michiels, J.; Skrivanova, E.; Missotten, J. et al., 2011: Intact Brown Seaweed (Ascophyllum nodosum) in Diets of Weaned Piglets: Effects on Performance, Gut Bacteria and Morphology and Plasma Oxidative Status. In: Journal of Animal Physiology and Animal Nutrition; doi: 10.1111/j.1439-0396.2011.01227

Molina Grima, E.; Belarbi, E.H.; Acién Fernández, F.G. et al., 2003: Recovery of Microalgal Biomass and Metabolites: Process Options and Economics. In: Biotechnology Advances 20/7-8 (2003), pp. 491-515 Muller-Feuga, A., 2004: Microalgae for Aquaculture: The Current Global Situation Future Trends. In: Richmond, A. (ed.): Handbook of Microalgal Culture: Biotechnology and Applied Phycology. Oxford, pp. 352-364 Muller-Feuga, A.; Moal, J.; Kaas, R., 2003a: The Microalgae of Aquaculture. In: Støttrup, J.G.; McEvoy, L.A. (eds.): Live Feeds in Marine Aquaculture. Oxford, pp. 206-252

Muller-Feuga, A.; Robert, C.; Cahu, J. et al., 2003b: Uses of Microalgae in Aquaculture. In: Støttrup, J.G.; McEvoy, L.A. (eds.): Live Feeds in Marine Aquaculture. Oxford, pp. 253-299

Nakagawa, H., 1997: Effect of Dietary Algae on Improvement of Lipid Metabolism in Fish. In: Biomedicine and Pharmacotherapy 51/8 (1997), pp. 345-348 Nandeesha, M.C.: Gangadhara, B.; Manissery, J.K. et al., 2001: Growth Performance of Two Indian Major Carps, Catla (Catla catla) and Rohu (Labeo rohita) Fed Diets Containing Different Levels of Spirulina platensis. In: Bioresource Technology 80/2 (2001), pp. 117-120

Nath, P.R.; Khozin-Goldberg, I.; Cohen, Z. et al., 2012: Dietary Supplementation with the Microalgae Parietochloris incisa Increases Survival and Stress Resistance in Guppy Poecilia reticulata Fry. In: Aquaculture Nutrition 18/2 (2012), pp. 167-180

Natrah, F.M.I.; Kenmegne, M.M.; Wiyoto, W. et al., 2011: Effects of Micro-algae Commonly Used in Aquaculture on Acyl-homoserine Lactone Quorum Sensing. In: Aquaculture 317/1-4 (2011), pp. 53-57

Olvera-Novoa, M.A.; Dominguez-Cen, L.J.; OliveraCastillo, L., 1998: Effect of the Use of the Microalgae Spirulina maxima as Fish Meal Replacement in Diets for Tilapia, Oreochromis mossambicus Fry. In: Aquaculture Research 29/10 (1998), pp. 709-715

Palmegiano, G.B.; Agradi, E.; Forneris, G. et al., 2005: Spirulina as a Nutrient Source in Diets for Gro- 
wing Sturgeon (Acipenser baeri). In: Aquaculture Research 36/2 (2005), pp. 188-195

Parisenti, J.; Beirão, L.H.; Maraschin, M. et al., 2011: Pigmentation and Carotenoid Content of Shrimp Fed with Haematococcus pluvialis and Soy Lecithin. In: Aquaculture Nutrition 17/2 (2011), pp. e530-e535

Pulz, O.; Gross, W., 2004: Valuable Products from Biotechnology of Microalgae. In: Applied Microbiology and Biotechnology 65/6 (2004), pp. 635-648

Sergejevová, M.; Masojídek, J., 2011: Chlorella Biomass as Feed Supplement for Freshwater Fish: Sterlet, Acipenser ruthenus. In: Aquaculture Research; doi:10.1111/j.1365-2109.2011.03011.x

Sheikhzadeh, N.; Tayefi-Nasrabadi, H.; Khani Oushani, A. et al., 2012: Effects of Haematococcus pluvialis Supplementation on Antioxidant System and Metabolism in Rainbow Trout (Oncorhynchus mykiss). In: Fish Physiology and Biochemistry 38/1 (2012), pp. 413-419; doi 10.1007/s10695-011-9519-7

Shields, R.J., 2001: Larviculture of Marine Finfish in Europe. In: Aquaculture 200/1-2 (2001), pp. 55-88

Shpigel, M.; McBride, S.C.; Marciano, S. et al., 2005: Improving Gonad Colour and Somatic Index in the European Sea Urchin Paracentrotus lividus. In: Aquaculture 245/1-4 (2005), pp. 101-109

Silva-Aciares, F.R.; Riquelme, C.E., 2008: Comparisons of the Growth of Six Diatom Species Between Two Configurations of Photobioreactors. In: Aquacultural Engineering 38/1 (2008), pp. 26-35

Silva-Neto, J.F.; Nunes, A.J.P.; Sabry-Neto, H. et al., 2012: Spirulina Meal has Acted as a Strong Feeding Attractant for Litopenaeus vannamei at a Very Low Dietary Inclusion Level. In: Aquaculture Research 43/3 (2012), pp. 430-437

Skrede, A.; Mydland, L.T.; Ahlstrøm, Ø. et al., 2011: Evaluation of Microalgae as Sources of Digestible Nutrients for Monogastric Animals. In: Journal of Animal and Feed Sciences 20/1 (2011), pp. 131-142

Soler-Vila, A.; Coughlan, S.; Guiry, M.D. et al., 2009: The Red Alga Porphyra dioica as a Fish-feed Ingredient for Rainbow Trout (Oncorhynchus mykiss): Effects on Growth, Feed Efficiency and Carcass Composition. In: Journal of Applied Phycology 21/5 (2009), pp. 617-624 Støttrup, J.G., 2003: Production and Nutritional Value of Copepods. In: Støttrup, J.G.; McEvoy, L.A. (eds.): Live Feeds in Marine Aquaculture. Oxford, pp. 145-205

Strand, A.; Herstad, O.; Liaaen-Jensen, S., 1998: Fucoxanthin Metabolites in Egg Yolks of Laying Hens. In: Comparative Biochemistry and Physiology 119/4 (1998), pp. 963-974
Tredici, M.R., Biondi, N.; Ponis, E. et al., 2009: Advances in Microalgal Culture for Aquaculture Feed and Other Uses. In: Burnell, G.; Allan, G. (eds.): New Technologies in Aquaculture: Improving Production Efficiency, Quality and Environmental Management. Cambridge, pp. 611-676

Turner, J.L.; Dritz, S.S.; Higgins, J.J. et al., 2002: Effects of Ascophyllum nodosum Extract on Growth Performance and Immune Function of Young Pigs Challenged with Salmonella typhimurium. In: Journal of Animal Science 80/7 (2002), pp. 1947-1953

Valente, L.M.P.; Gouveia, A.; Rema, P. et al., 2006: Evaluation of Three Seaweeds Gracilaria bursa-pastoris, Ulva rigida and Gracilaria cornea as Dietary Ingredients in European Sea Bass (Dicentrarchus labrax) Juveniles. In: Aquaculture 252/1 (2006), pp. 85-91

Viçose, G.C. de; Viera, M.PP.; Huchette, S. et al., 2012: Improving Nursery Performances of Haliotis tuberculata coccinea: Nutritional Value of Four Species of Benthic Diatoms and Green Macroalgae Germlings. In: Aquaculture 334-337 (2012), pp. 124-131

Waldenstedt, L.; Inborr, J.; Hansson, I. et al., 2003: Effects of Astaxanthin-rich Algal Meal (Haematococcus pluvialis) on Growth Performance, Caecal Campylobacter and Clostridial Counts and Tissue Astaxanthin Concentration of Broiler Chickens. In: Animal Feed Science and Technology 108/1-4 (2003), pp. 119-132 Walker, A.B.; Berlinsky, D.L., 2011: Effects of Partial Replacement of Fish Meal Protein by Microalgae on Growth, Feed Intake, and Body Composition of Atlantic Cod. In: North American Journal of Aquaculture 73/1 (2011), pp. 76-83

Zatkova, I.; Sergejevová, M.; Urban, J. et al., 2011: Carotenoid-enriched Microalgal Biomass as Feed Supplement for Freshwater Ornamentals: Albinic Form of Wels Catfish (Silurus glanis). In: Aquaculture Nutrition 17/3 (2011), pp. 278-286

Zmora, O.; Richmond, A., 2004: Microalgae for Aquaculture: Microalgae Production for Aquaculture. In: Richmond, A. (eds.): Handbook of Microalgal Culture: Biotechnology and Applied Phycology. Oxford, pp. 365-379

\section{Contact}

Dr. Robin J. Shields and Dr. Ingrid Lupatsch

Centre for Sustainable Aquatic Research

Swansea University

Singleton Park, Swansea, SA2 8PP, Great Britain

E-mail: r.j.shields@swansea.ac.uk

E-mail: i.lupatsch@swansea.ac.uk 